\title{
Citizens' views on the practices of zero-grazing and cow-calf separation in the dairy industry: Does providing information increase acceptability?
}

\author{
Maria J. Hötzel, ${ }^{* 1}$ Clarissa S. Cardoso, ${ }^{*}$ Angélica Roslindo, ${ }^{*}$ and Marina A. G. von Keyserlingk† \\ *Laboratório de Etologia Aplicada e Bem-Estar Animal, Departamento de Zootecnia e Desenvolvimento Rural, \\ Universidade Federal de Santa Catarina, Florianópolis, 88034-001, Brazil \\ †Animal Welfare Program, Faculty of Land and Food Systems, The University of British Columbia, Vancouver, V6T 1Z4, Canada
}

\begin{abstract}
The primary aim of this study was to assess the influence of provision of information on lay citizens' opinions regarding 2 common management practices, zero-grazing and cow-calf separation. To aid in the interpretation of the findings, our secondary aim was to explore the awareness and opinions of Brazilian citizens about these practices. We surveyed a convenience sample of Brazilian citizens (192 men and 208 women), recruited in a public place, with the majority stating that they were largely unfamiliar with animal production and lived in urban environments. Participants were presented short scenarios with information on the primary production factors and welfare concerns for and against zero-grazing $(\mathrm{n}=200)$ or cow-calf separation $(n=200)$. Participants were then asked to state their position (reject, indifferent, or support), and to provide the reason(s) justifying their position. Immediately following, participants were provided a short statement describing either zero-grazing or cow-calf separation, depending on what question they responded to in the first part. Two closed questions (Q) followed each of these statements: (Q1) "Are you aware of this practice?" with choices yes, somewhat, or no, and (Q2) "What is your position regarding this practice?" with choices reject, indifferent, or support. Only 31 and $33 \%$ of the respondents were aware of zero-grazing and cow-calf separation, respectively. Previous awareness of existence of practice did not influence levels of support. Provision of information resulted in more people rejecting the practices of zero-grazing and cow-calf separation. Participants' main justifications to reject zero-grazing and cow-calf separation focused on perceived negative effects of practices on farm animal welfare and product quality, and loss of naturalness. Survey participants, Brazilians living in urban environments, with little or
\end{abstract}

Received August 29, 2016.

Accepted January 16, 2017.

${ }^{1}$ Corresponding author: maria.j.hotzel@ufsc.br no association with dairy production, were generally unaware that many cows do not have access to pasture and that cows are separated from their calf at birth. Independent of provision of additional information, most participants did not support these practices. Provision of brief explanatory information played a minor role in influencing people's views, but failed to result in general acceptance.

Key words: animal welfare, public attitude, public perception, survey

\section{INTRODUCTION}

The lay public, in contrast to agriculture industry specialists and farmers, frequently rate farm animal husbandry practices as detrimental to animal welfare (Vanhonacker et al., 2008; Benard and de Cock Buning, 2013; Ventura et al., 2013). Negative attitudes expressed by the public toward animal production have been argued by some to be a consequence of ignorance of the realities of animal production (Capper, 2011; You et al., 2014; Pieper et al., 2016). Many working within farm animal production thus argue that educating the public should result in greater acceptance of current management practices (discussed by Ventura et al., 2016). This apparent disconnect between how members of society that are not routinely involved with animal production and those that are actively involved view animal agriculture may be a consequence of different viewpoints. Reasons in support of, or opposed to, a particular farming practice may be science-based, practical, economic, or ethical in nature (see review by Weary et al., 2016). In many cases, even in the absence of evidence to support these claims, lay citizens frequently prefer systems they perceive as natural (see review by Clark et al., 2016).

That the public question some farm animal management practices is not surprising. For example, inflicting pain on animals is considered by many to be abhorrent (Weary et al., 2006). However, despite ample sciencebased evidence indicating that dehorning is painful and the availability of well-established pain-mitigation protocols (Stafford and Mellor, 2011), many producers still 
routinely dehorn without pain management [United States: Fulwider et al. (2008); Canada: Vasseur et al. (2010) and Winder et al. (2016); Brazil: Hötzel et al. (2014); Europe: Cozzi et al. (2015)].

Two additional dairy production practices that are common on many dairy farms but are also viewed as being contentious are early cow-calf separation (Ventura et al., 2013) and housing dairy cattle in zero-grazing systems (Schuppli et al., 2014). Reasons provided by proponents of early separation include perceived assurances that the calf is properly nourished and cared for, improved calf health, reduced stress for the dam (and the calf) associated with early separation, and increased practicality given the challenges associated with keeping cows and calves together (Mee, 2008; Ventura et al., 2013). In contrast, those that argue against early separation cite lack of naturalness, emotional pain, and poor health for both the dam and the offspring (Ventura et al., 2013). Many working in the dairy industry justify zero-grazing systems on the basis that the nutrient intake of the cow can be controlled through the provision of formulated diets, that grazing results in lower milk production, and results in putative economic and environmental advantages (Schuppli et al., 2014). Those in favor of grazing cite naturalness, the ability of the cow to breathe fresh air, freedom of movement, and improved cow health status (Schuppli et al., 2014).

A growing body of evidence indicates public opposition to early separation of the cow and calf, as well as lack of pasture access for dairy cattle (Boogaard et al., 2011; Ventura et al., 2013; Schuppli et al., 2014; Cardoso et al., 2016). One very recent study (Ventura et al., 2016), involving face-to-face interviews with 50 members of the Canadian public that had little or no experience with dairy farming, highlighted zero-grazing and cow-calf separation as particularly contentious for the participants. In fact, attitudes regarding the welfare of cattle on dairy farms, which were initially primarily positive, declined after the participants visited a dairy farm. The fact that the majority of participants were unaware of the practice of early separation and that most lactating cows were not provided access to pasture resulted in a large number of the participants losing confidence that dairy cows have a good life.

Cow-calf separation at birth is a common management practice used on Brazilian dairy farms (Hötzel et al., 2014; dos Santos and Bittar, 2016). Despite most Brazilian cows having some access to pasture year-round (Costa et al., 2013), an increasing number of dairy cows are being housed in zero-grazing systems, likely in response to increases in milk demand and policies that favor intensification (von Keyserlingk and Hötzel, 2015; Balcão et al., 2017). Despite Brazil's growing position in the production of animal products (e.g., milk, animal protein), little is known about the views from citizens of the country regarding animal production (von Keyserlingk and Hötzel, 2015).

The primary aim of our study was to assess the influence of provision of information on lay citizens' opinions regarding 2 common management practices: zero-grazing and cow-calf separation. To aid in the interpretation of the findings, our secondary aim was to explore the awareness and opinions of Brazilian citizens about these practices.

\section{MATERIALS AND METHODS}

This research was approved by the Ethics Committee of Research with Human Beings of Federal University of Santa Catarina, Brazil. Lay citizens were recruited at the International Airport Hercílio Luz, in Florianópolis, during the months of January and February 2016. The location was chosen due to the intense movement of people and waiting times, which provided the opportunity to identify respondents of both sexes, based on our intent that there be a 50:50 sex balance. Individuals were asked to voluntarily participate in the survey if they met certain conditions: be at least 18 years old, a Brazilian citizen, and interested in answering a short questionnaire in Portuguese covering the general theme animal production. The material presented describing cow-calf separation and zero-grazing practices was adapted from Ventura et al., (2013) and Schuppli et al., (2014), respectively. Upon verbal agreement to participate, the participant was asked to sign a consent form and given a 3-page printed questionnaire to fill out. The researcher remained visible to answer questions, but did not provide any information on either of the topics while the participant filled out the questionnaire.

All consenting participants began the survey by answering 8 closed demographic questions, including sex, age, schooling, region of origin (urban/rural), and self-assigned knowledge of dairy production in Brazil. Participants were then randomized into 2 treatment groups. Group A participants were provided an information capsule describing cow-calf separation, adapted from that described by Ventura et al. (2013). Two main changes were made to the original text; first, we positioned the argument regarding the amount of milk consumed as the first argument rather than the latter argument, as was the case in the Ventura et al. (2013) study. This was done given that all of our participants were, by design, not familiar with the dairy industry, which was in contrast to Ventura et al. (2013), which had a more heterogeneous participant pool. Second, given that much of the Brazilian dairy industry still uses pasture, we modified the wording of one sentence in the original text, from "On many dairy farms cows 
are always kept indoors" to "On some dairy farms cows are kept in barns, without access to pasture," to better portray the reality of the Brazilian situation used by Schuppli et al. (2014). The information capsule for group A was as follows:

"Dairy farmers generally remove the calf from the cow within the first few hours of birth. This is done in response to several concerns, including the following: the calf will drink too much milk, which increases the farmer's cost of feeding and increases the risk of diarrhea; allowing the cow and calf to bond will result in greater separation distress when separation does occur; the calf may become infected from pathogens carried by the cow or her environment; the calf may become injured by the cow or the barn equipment; the calf will not be able to nurse from the cow and receive adequate colostrum (first milk produced by the cow after birth) and milk; farms are often not well designed for cow-calf pairs, so keeping cows and calves together can be considered an extra chore. Others consider that cow-calf contact is an important element of natural behavior, and believe that this contact is beneficial to the cow and calf. On these farms the cow and calf are kept together for days or even weeks after birth."This was then followed by the question, "What is your position regarding this practice?" (reject/indifferent/support), and the statement, "Please justify your answer."

Last, group A participants were then provided the following short written statement: "In some dairy farms cows are reared in barns without access to pasture throughout their lactation." This statement was followed by 2 closed questions: (1) "Are you aware of this practice?" with options yes/vaguely/no, and (2) "What is your position regarding this practice?" with options reject/indifferent/support.

Alternatively, group B participants were provided the following information capsule describing zero-grazing, based on the description of Schuppli et al. (2014), but with the first sentence modified as described above:

"On some dairy farms cows are kept in barns, without access to pasture. Some dairy farmers believe that well-designed indoor housing provides a more comfortable and more suitable environment for the cows. In addition, some farmers keep cows indoors to more easily provide and control diets formulated to sustain high milk production. Others consider that it is important that milking cows have access pasture. The justifications for this are that grazing is more environmentally sustainable, that pasture provides a healthier and more comfortable environment for cows, and that grazing is a natural behavior important for cows."This was then followed by the question, "What is your position regarding this practice?" (reject/indifferent/ support), and the statement, "Please justify your answer."

In the final part of this survey, group B participants were provided the following short written statement: "On dairy farms the calf is separated from its mother shortly after birth." This statement was then followed by 2 closed questions: (1) "Are you aware of this practice?" with options yes/vaguely/no, and (2) "What is your position regarding this practice?" with options reject/indifferent/support.

The ideal sample for qualitative analysis is one that reflects all of the multiple dimensions of the objective of the research; that is, when answers start repeating within a particular theme (Robson, 1993; Minayo, 2008). In other words, research responses (data) were collected until no new ideas or concepts were identified (i.e., data saturation was reached). In the present study, saturation was achieved at about 200 respondents for each of the identified themes. Thus, to obtain sufficient sample size for the quantitative analyses, we interviewed 400 respondents (200 for each question).

Open responses were free coded to identify major themes within and across participant responses, following the methodology described by Huberman and Miles (1994). Briefly, this followed a standard procedure that involved data reduction (information was coded into specific themes), data display (information was organized to allow for conclusions to be drawn), and conclusion-drawing and verification (noting of patterns and themes and using triangulation between 3 readers). For example, the theme "natural" in the question regarding zero-grazing arose from individual responses that expressed ideas that were classified into codes, including "natural behavior," "natural living environment," "natural feed/feeding" or "low or no use of chemical inputs in feed-antibiotics, pesticides, hormones," "natural evolution," "natural physiological process," "natural as opposed to object," "nature/ecology," and direct use of the term "natural." Respondents used, on average, 22 and 43 words to justify their choice on the zero-grazing and cow-calf separation questionnaire, respectively. The lead author and the third author, plus an additional trained social science researcher (M. C. Yunes, Universidade Federal de Santa Catarina), independently examined 25 randomly selected responses in each questionnaire, coded them, and classified them in themes. Results were then compared between the 
3 coders and any discrepancies reconciled. The lead author then undertook the remaining analyses.

Major themes identified in the initial analysis of the interview transcripts are described in the Results section. The focus of the analysis is not to make inferences regarding the prevalence of a given idea/concept (themes) within the group of respondents, but rather to describe the variation of ideas that the group expresses regarding the issue (Robson, 1993; Minayo, 2008); thus, some codes and themes were identified in many responses, whereas others were identified in only a few responses. Quotes were selected to represent examples of excerpts within responses that were classified under a given code within each theme; preference was given to statements that contained a concept shared by many responses, or those that better expressed a given concept.

For quantitative analysis of the closed questions, chi-squared tests were used to test for associations of previous awareness of the practice and the effect of providing an information text or a statement describing zero-grazing or cow-calf separation, on answering reject/indifferent/support the same practice, and the demographic data between the 2 groups.

\section{RESULTS}

Demographic data of participants in each group are described in Table 1. Most participants had post-secondary education, were largely unfamiliar with animal production, and lived in urban environments. Most respondents (84\%) lived in the south and southeast regions of the country. None of the demographic variables differed between the 2 groups $(P>0.05)$.

\section{Influence of Awareness and Provision of Information on Support for Practices}

Support for both zero-grazing $(P<0.04)$ and cowcalf separation $(P<0.001)$ was influenced by provision of information (Table 2). Only 31\% respondents were aware of zero-grazing and $33 \%$ of cow-calf separation. Previous awareness of existence of practice did not influence levels of support $(P=0.25)$.

\section{Reasons Given in Support Of or Against Zero- Grazing and Early Cow-Calf Separation}

Responses of participants assessing the zero-grazing question were coded into 5 main themes (in descending order of percent of total respondents that provided these reasons): naturalness $(50 \%)$, animal welfare $(45 \%)$, influence of feeding and housing practices on milk quality (19\%), environmental impacts of cow feeding systems
(11\%), and criticisms to a perceived preeminence of productivity and profit over other food animal production goals (10\%). Reasons conveyed by the respondents (R) regarding early cow-calf separation were coded into 4 main themes: naturalness $(30 \%)$, importance of early contact for both the cow and the calf (28\%), ethical concerns (26\%), and animal feelings or suffering (9\%).

\section{Reasons Given in Support Of or Against Zero-Grazing}

Naturalness. The word "natural" appeared in 72 of the 172 reasons presented and referred primarily to the living environment provided for the animals ("...she should be in touch with nature, she is a farm animal," R166), their feed ("Consuming natural foods and not only compounds that seek to increase the volume of milk; preventing the stress of confinement too," R97), their behavior ("I believe that even with formulated diets for increased production, cows must have access to pasture, because this is an animal behavior...," R159), and ecological interactions, or environmental sustainability ("Removing something that is natural for an animal is always a step backward in environmental terms," R26). Some respondents equated naturalness with a less stressful environment. Some considered naturalness to be integral to the production process ["Cows must have the natural cycle of production, i.e., they should have access to their natural environment (pasture) to feed," R111], and in some cases specific to the lactation process ("... we must make the lactation as natural process as possible," R25). Some respondents associated the loss of naturalness with the objectification of animals ("It is the natural way, they are not machines or objects," R65). Finally, some respondents simply stated, "it is natural" or "it is more natural," but failed to quality this statement.

Animal Welfare. Aspects of animal life included explicit mention of animal welfare, freedom to move, animal comfort, health, stress, or ability to perform natural behaviors. For example, "I believe that access to pasture decreases the animal's stress" (R146); "I believe that being confined for a long period is not pleasant nor healthy" (R120); "... concrete flooring can lead to problems in the joints, while pasture can provide greater social interaction" (R2); and "With dairy cows grazing natural pasture, the milk is healthier and also the cows are more comfortable" (R34).

Influence of Feeding and Housing Practices on Milk Quality. The use of additives in support of milk production was a salient concern among our respondents. Some expressed uncertainty regarding the use of chemical additives to produce milk ("Thus avoiding the use of hormones that may be present in other types 
Table 1. Demographics of the groups that participated in the survey where they were asked to respond regarding their awareness and opinion about early cow-calf separation and zero-grazing for dairy cows ${ }^{1}$

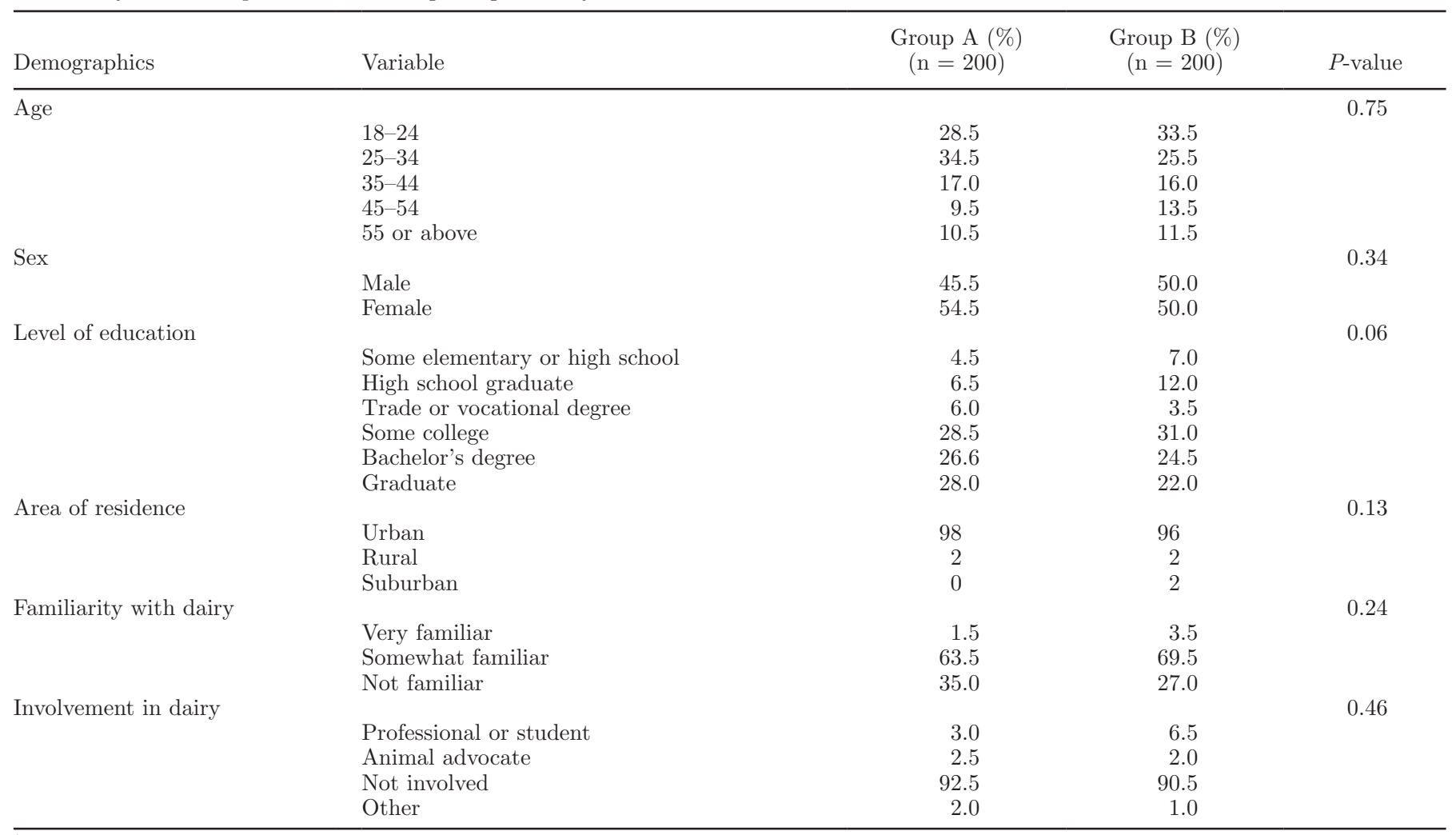

${ }^{1}$ Group A $(\mathrm{n}=200)$ participants were provided an information capsule describing early cow-calf separation followed by a short statement regarding zero-grazing; Group B $(\mathrm{n}=200)$ participants were provided an information capsule describing zero-grazing followed by a statement regarding early cow-calf separation.

of food," R9; "Yes, because I think there would be less need for medication and steroids for milk production," R165), but others presented this as a fact ("Formulated diets have many chemicals that are not good for you; I am in favor of pasture," R190; "With cows on pasture during the lactation period we will have a more pure

Table 2. The percentage of participants who either rejected, were indifferent, or supported zero-grazing systems for dairy cows or early cow-calf separation ${ }^{1}$

\begin{tabular}{lccc}
\hline Topic & $\begin{array}{c}\text { Information } \\
\text { capsule }\end{array}$ & $\begin{array}{c}\text { Short } \\
\text { statement }\end{array}$ & $P$-value \\
\hline Zero-grazing & 86.1 & 75.7 & 0.04 \\
$\quad$ Reject & 12.2 & 20.5 & \\
Indifferent & 1.7 & 3.8 & \\
$\quad$ Support & 69.2 & 61.7 & 0.001 \\
Cow-calf separation & 17.3 & 32.8 & \\
$\quad$ Reject & 13.5 & 5.6 & \\
Indifferent & & \\
Support & &
\end{tabular}

${ }^{1}$ Participants $(\mathrm{n}=400)$ were first provided an information capsule describing either early cow-calf separation or zero grazing, after which they were given a short statement describing the other practice (e.g., participants that were provided an information capsule describing zerograzing were given a short statement on early cow-calf separation). milk, without chemicals, which may even harm the health of those who consume it," R181).

Some expressed a perceived association between higher quality of milk and natural diets ("Because I believe that cows should have a minimum of interaction with the natural environment, so as not to be fully fed with artificial diets. I think that this form of management may reflect in the quality of milk," L98), or animal welfare ("Animal welfare, which provides greater biological value and quality to milk," R23).

Perceived Preeminence of Productivity and Profit over Other Goals. Some respondents expressed concerns regarding what they perceived as an absolute requirement for productivity and profit over other farming goals. For example, "Keeping cows out of their natural conditions for profit is absurd, though it is an accepted practice for capitalists who only seek their own satisfaction: "make more profit"' (R180); and "Finding a balance between profit and nature is the challenge of this century" (R26). When answering that cows should have access to pasture, a participant said, "I think so, to increase animal welfare. I find it important that the industry that deals with animal 
products work with an ethical perspective and not just economic," (R4).

Environmental Impacts of Cow Feeding Systems. Finally, the few respondents that expressed concerns about environmental impact of cow access to pasture believed grazing to provide positive benefits for both the cow and the environment. A small number of participants positioned themselves as indifferent and justified their indifference by indicating a lack of understanding of the production system per se; some also suggested that they would need more technical information and a third did not justify. Of the 5 participants that supported zero-grazing, 1 failed to give a reason why and 4 argued that zero-grazing systems were better for the cows health, nutrition or production ("Cows raised in barns live on diets to sustain high milk production and have all the comfort they need," R169).

\section{Reasons Given For or Against Cow-Calf Separation}

Naturalness and Importance of Early Contact for Both the Cow and the Calf. Thirty-six percent of the respondents that opposed separation cited the reason that early contact is important for both the cow and the calf: "Contact with the mother is essential for all species" (R398). When referring to the early mother-young interaction, respondents used words such as "need," "must," or "deserve" to be together, or that early mother young contact is "important," "beneficial," "primordial," or "natural." Some explicitly stated that they were repulsed by this practice.

Naturalness of the mother-young contact was referred to by over $30 \%$ of opposed respondents ["I think the calf should not be separated from the mother, because it is natural that it is always close to its mother, as any newborn," R238; "No, since at birth any individual (regardless of species) needs maternal care as part of a natural process," R385]. One respondent suggested long-term effects of the early contact: "I believe that the mother-young contact is healthy...the mind and the body in some way will eventually save this pleasurable experience, which will result in a healthier, more resistant animal" (R347).

Ethical Concerns. Some respondents used terms such as "not right," "inadmissible," "unfair," "deserve," or "respect" to express their ethical disapproval of early cow-calf separation; some believed that production goals are favored over the interests of the animals. For example, "They are mammals, they must suckle, not be treated as "resources" (R214); "It is not right to separate cows from their young just to increase milk production" (R216); and "Separating the calf from its dam at birth implies in depriving it of its natural needs at that initial phase of its life. Breaking this relation- ship for pure economic and utilitarian interests shows the anthropocentric character of humans" (R257). One respondent recognized his lack of knowledge, but placed the burden of improving the system on the farmers: "I do not have in-depth knowledge of the subject, but I believe contact between the cow and her young is important. I think it would be interesting that dairy farmers should design farms to enable this proximity and interaction between cow and calf" (R297).

Animal Feelings or Suffering. Respect for the feelings of animals and a belief that separation or prevention of the early contact will cause suffering was discussed by many of the participants. For example, "I believe that animals have feelings, maybe not the same as humans, and separation may affect the development of the animals" (R357); "Cows have their feelings, and the pain (of separation) must be the same as in a mother" (R273); and "I believe that the stimulus generated by the calf sucking and the emotional connection between them are beneficial both for the quality of the product and the health of animals" (R383). In their reasons provided in support of early cow-calf separation, participants mentioned the justifications provided in the information text, some using the same words. Nine respondents made it clear that their position was influenced by information cited within the text (e.g., "Until now I was unaware of the points presented above," R312; "According to the text the separation is done for the good of the calf," (R364).

Participants that positioned themselves as indifferent to the practice reported lack of understanding or suggested that they believed farmers had reasons to use early cow-calf separation, and 3 commented that they saw positive as well as negative aspects. For example, "I don't know to what extent we can extrapolate our feelings and apply them to animals. I am certainly in favor of reducing the impact of productivity on the animals, but the subsequent increase in price may make feeding families unfeasible" (R8); and "I am not in favor of separating the calf from the mother, but it is for the common good..." (R166).

\section{DISCUSSION}

Survey participants, Brazilians largely living in urban environments and with little or no association with dairy production, were generally unaware that cows are separated from their calf at birth and that an increasing number of cows are reared in zero-grazing systems. However, despite the prevalence of these practices (Spers et al., 2013; Hötzel et al., 2014; von Keyserlingk and Hötzel, 2015; dos Santos and Bittar, 2016), when participants were asked their opinion most did not sup- 
port either of these 2 practices. The group provided with information justifying the practices and discussing some of their limitations and criticisms showed higher rejection of both practices. Our results provide evidence indicating that low awareness and knowledge of how food animals are reared (Clark et al., 2016) does not fully explain public rejection of some production practices.

Fewer participants that were provided descriptive information, instead of just a short statement about the practice, were indifferent to both practices; although information resulted in slightly more participants supporting cow-calf separation, overall there was greater rejection of both practices. Other studies have shown that providing information regarding dairy management (Ventura et al., 2016), gestation stall housing for sows (Ryan et al., 2015), or layer hens' housing (Bennett et al., 2016) does not improve overall lay citizens' attitudes, and identified animal welfare as a main reason behind low acceptability of animal housing and management practices. As in the present study, others have shown that often lay citizens justify their negative attitudes regarding livestock production practices with misconceptions (Robbins et al., 2015), or ignore issues that are deemed highly relevant by stakeholders with scientific and technical understanding of the production system (Pettersson et al., 2016). In some cases, even the presentation of information highlighting specific welfare and health problems of free-range housing for chicken has failed to influence participants' perceptions that the system is superior for animal welfare. One example involved a representative sample of UK egg consumers $(\mathrm{n}=1,776)$ asked to rate the welfare of free-range hens (Bennett et al., 2016). Only half of the participants received information regarding injurious pecking in free-range chicken, including the fact that it is a highly prevalent condition among free-range hens, with substantial welfare and financial implications. This did not, however, influence the mean welfare score attributed to free-range systems (78.2 vs. 78.8 for participants that received or did not receive information, respectively), which in both cases was significantly higher than the welfare scores assigned to cage systems. In another example, Dutch citizens were presented a hypothetical scenario in which they were told that by changing from a conventional to a free-range system Campylobacter contamination rates would increase from 10 to $30 \%$ in broiler chickens, which may cause intestinal infections in humans. The respondents that were opposed to the change $(12 \%)$ argued that consumers had a right to buy meat with minimal bacterial contamination; the respondents who favored the change to free-range system (42\%), however, attributed a greater importance to arguments concerning broiler bird welfare, such as longevity and expression of natural behaviors (van Asselt et al., 2016).

Previous work has indicated that lay citizens' views of the use of technologies by agriculture may be influenced by the type of information provided (Cuite et al., 2005) and how trustworthy the source of information is perceived to be (Hansen et al., 2003; Tonsor and Wolf, 2010; Frewer et al., 2014); both factors may explain some of our results. Our information texts provided arguments for and against zero-grazing and cow-calf separation. As with most situations, citizens may receive different types of information from different sources - ranging from information in support of a particular practice generated by animal industries and retailers in marketing campaigns and product packages, to negative information rejecting current practices from critics such as animal protection societies (Fraser, 2001).

Experimenting on how different types of information shaped the attitudes of participants toward the proposal presented in the California 2008 ballot initiative, Proposition 2 ("a person shall not tether such an animal for most the day in a manner that prevents the animal from lying down, standing up, fully extending its limbs, and turning around freely"), Richards et al. (2013) concluded that information presented in this kind of exercise might convey to many people the notion that farm animals may be mistreated. The fact that our respondents seemed largely unaware of the 2 practices implies that much of the information was new to them. As Richards et al. (2013) explained, based on citizens' ignorance of the realities of animal production and on the assumption that farm animals are happy, any "small amount of bad news regarding animal welfare was enough to outweigh many strong, but conventional economic arguments." Although the reasons presented in the cow-calf information text caused a few of the participants in our study to support the practice, others showed surprise regarding the reasons alleged for this practice. The conclusions of Richards et al. (2013) may also explain the decline in Canadian citizens' attitudes toward animal welfare in dairy farms after a farm visit promoted by the researchers (Ventura et al., 2016): the decline reported by those authors was mostly based on becoming aware of (and opposed to) cow-calf separation and insufficient access to pasture during the farm visit.

It has been argued that one reason citizens' opinions on contentious issues of agriculture differ from expert opinion is that the former are greatly influenced by perceptions of risk and ethical assessments; for example, regarding effects on human health and animal welfare (Hansen et al., 2003; Hötzel, 2016). This point is supported in the justifications provided by our participants. 
First, animal welfare and loss of naturalness were the 2 most salient concerns raised by participants that rejected both zero-grazing and early cow-calf separation. Second, participants that rejected zero-grazing systems expressed concerns about the influence of production practices on product quality and, potentially, human health.

Participants expressed their concerns regarding animal welfare, stating a belief that animals are sentient beings with capacity to suffer and have positive emotional states; the ability of animals to express their natural behaviors was also important for many. These concerns echo studies with citizens from other countries (Boogaard et al., 2008; Ellis et al., 2009; Prickett et al., 2010; Cardoso et al., 2016). The same utilitarian assessment was used by UK citizens that were somewhat favorable to genetic modification techniques to animals for the purpose of medical research for humans, but not for commercial benefits (Macnaghten, 2004). Many argue that technologies and production practices that improve the economic efficiency of livestock production systems benefit farmers and the animal industries, but also consumers, by reducing the cost of food products. However, confusion arises when, despite some people agreeing that animal welfare is more important than the cost of food products (Wolf et al., 2016), this view fails to directly translate into willingness to pay for animal-friendly products or buying choices (Harvey and Hubbard, 2013). Others have argued that using willingness to pay as a means to justify particular practices is risky, as this places the sustainability of the animal industries on the shoulders of consumers, arguably an uninformed stakeholder (von Keyserlingk et al., 2013). This argument has gained some traction given the growing body of evidence showing that citizens acting as voters rarely consider the potential increase in cost implicated in changing agricultural practices (Tonsor and Wolf, 2010).

The concept of naturalness, a value with strong traction among the lay public when assessing animal production systems (Lassen et al., 2006; Miele, 2010; Prickett et al., 2010; Boogaard et al., 2011), was frequently highlighted by our participants; this included specific references to the animals' need to express natural behaviors and to have contact with nature and to food produced by natural methods. The ability of animals to express natural behaviors, both in the context of mother-young contact and access to pasture, was an important concern for almost a third of respondents, suggesting a strong connection between naturalness and the concept of animal welfare (Fraser et al., 1997). Some of the justifications for rejection of the practices suggest that for some participants the appeal to naturalness may be in response to the stress of everyday modern life, which contact with nature would ease (Macnaghten, 2004). Among possible interpretations of the natural concept revered by organic stakeholders (Verhoog et al., 2003) is the perceived relation to the concept of respect for the integrity of animal species. This may imply for example, that cows should be fed as ruminants and young mammals cared for by their mothers. Alternatively, classification of early cow-calf separation and zero-grazing as unnatural may be a consequence of the participants' desire to express a negative attitude (Nuffield Council on Bioethics, 2015) toward aspects of particular dairy production practices of which they were previously unaware. It has been suggested that people need to define unfamiliar things as compliant or divergent from the norm, and therefore frequently classify things (such as genetically modified organisms) as unnatural (Ribeiro et al., 2016). Indeed, many of our participants described keeping young animals with their mother or cows on pasture as the norm, and alternatives as aberrant. Modern animal production per se involves the use of several non-natural practices and technologies that have been developed to achieve production, environmental, and even animal welfare goals. Therefore, further understanding of the reasons underlying the apparent preference for naturalness may be needed to devise ways to increase acceptability of animal production systems among the lay public.

Finally, some participants that opposed zero-grazing expressed specific concerns regarding overuse of pesticides, antibiotics, or hormones. This concern has been reported in surveys involving citizens of different countries (Miele, 2010; You et al., 2014; Cardoso et al., 2016; Clark et al., 2016; Pieper et al., 2016; Wolf et al., 2016). Wide publicity in the media (Movimentos Sociais e Redes, 2016) given to the overuse of pesticides in Brazil (Jardim and Caldas, 2012), overuse of antibiotics for food production (Oliveira and Bonfanti, 2014), and milk frauds (Rodrigues, 2014) may explain the salience of this concern among our respondents.

Our findings add to previous works that have identified differing views between those who have experience and those who have no experience with farm animal production practices (Weary et al., 2016). The worry that the ongoing disconnect between lay citizens and animal industries may increase the risk of restrictive regulations, retailer initiatives, or consumer choices is shared by many (Brom, 2000; von Keyserlingk et al., 2013; Schuppli et al., 2014; Pieper et al., 2016). To avoid these potentially undesirable scenarios, some scientists propose that educating the public, via provision of easily comprehendible science-based information, may improve acceptance of modern agriculture practices and technologies (Croney et al., 2012; You et al., 2014; Pieper et al., 2016). To our knowledge, only one 
study has tested whether provision of information will increase acceptability of conventional dairy farming; however, the findings indicate that, although acceptability of some practices increased, awareness of previously unknown practices resulted in reduced confidence that dairy cows have a good life (Ventura et al., 2016). Given the dearth of these types of studies, we encourage additional research in this area, particularly as this may provide additional insights as to how lay citizens weigh different types of information. The notion that scientific information is unbiased and is the only legitimate source of information the public should use to assess agriculture is common, and can be exemplified in the conclusion of Capper (2011), that consumer choice "... should be an educated one based on science and logic rather than philosophical assumptions." However, this idea overlooks the fact that citizens' opinions regarding agriculture practices are influenced greatly by factors such as moral and ethical values regarding the lives of animals and the assessment of risk to human health involved in livestock production (Boogaard et al., 2011; Ryan et al., 2015; Hötzel, 2016; Ventura et al., 2016). For example, our respondents expressed in different ways the belief that animals should live a good life, and that a good life should not be prevented by productive goals. One contribution scientists may make to improve acceptance of modern agriculture practices - much needed to feed a growing world in a sustainable fashion (Godfray et al., 2010; Foley et al., 2011) - is to help design production systems that can answer simultaneously economic, technical, and ethical demands. It has been shown that, at least in some cases, consumers may not consider proposed alternatives that specifically address public concerns as being more acceptable than standard industry practices [e.g., dual use of chickens and in ovo sex determination vs. killing of day-old male chicks (Gremmen and Blok, 2016), or housing layers in furnished cages vs. conventional battery cages $(\mathrm{Lu}$, 2013)].

This is an exploratory study, based on a convenience sample of participants, and as such does not represent the views of the Brazilian society (IBGE, 2010). When compared with a representative sample of Brazilians, our sample contains a greater proportion of well-educated, urban, and, possibly, wealthy citizens than the Brazilian population. However, it contributes novel information on the attitudes of lay citizens toward livestock production practices, an issue explored in industrialized but not in developing countries (von Keyserlingk and Hötzel, 2015).

The main aim of our study was to understand how provision of information may influence attitudes of lay citizens regarding 2 contentious dairy production practices (Boogaard et al., 2011; Ventura et al., 2013;
Schuppli et al., 2014), and, by soliciting their subjacent reasons, to understand the results of our education exercise. We provided information with an overview of the main technical justifications employed by most working within the dairy industry for each practice and some common criticisms made by people outside the dairy industry. Some factors related to the information provided might have influenced our findings, such as the depth and scope, as well as the choice of issues listed in the information text; the fact that the information was depicted from the farmers' point of view, clearly an interested party, and trust in the source of the information may influence public perceptions toward agriculture practices and technologies (Robbins et al., 2016). Importantly, our decision to highlight certain points in a particular order within the information capsule may have also influenced the responses, as some participants may have understood the order of presentation of the factors listed as an indication of the degree of importance, which could have influenced their responses. Additionally, in this and other studies (Ryan et al., 2015; Ventura et al., 2016), economic and practical trade-offs associated with these contentious practices were not fully considered by participants. Last, in the case of the cow-calf separation argument, we did not tell the participants that keeping cows and calves together is an extremely rare practice on conventional dairy farms and only happens for limited periods in some organic systems (Asheim et al., 2016).

The North American surveys were applied online through an interactive platform that allowed the respondents to read, in addition to the information text provided by the researchers, the opinions and arguments of previous respondents, which challenged, completed, or emphasized the information originally presented by the researchers (Ventura et al., 2013; Schuppli et al., 2014). Opposition rates among lay citizens in those surveys ( $76 \%$ for cow-calf separation and $90 \%$ for zero-grazing) were comparable to the present study, as were the themes addressed by respondents in their justifications. Although the studies are not directly comparable, the similar rejection levels and underlying reasons identified in the North America studies and ours reinforces the conclusion that issues pertaining to animal welfare or naturalness values may be more important for lay citizens than additional technical and economic information, as also shown by others (Richards et al., 2013; Bennett et al., 2016; van Asselt et al., 2016). Finally, social desirability has been shown to influence responses in experiments involving willingness to pay for animal-friendly products (Lusk and Norwood, 2010). However, the current survey did not require participants to state if they would be willing to act on their attitudes. Likewise, social desirability 
bias may have been minimized by the way this survey was administered; that is, participants had no contact with the researcher, which has been shown to reduce potential bias when compared with face-to-face surveys (Heerwegh, 2009). Further studies addressing the effect of information on public attitudes toward livestock production practices may want to consider these limitations.

\section{CONCLUSIONS}

Survey participants-Brazilians living in urban environments with little or no association with dairy production - were generally unaware that many cows do not have access to pasture and that cows are separated from their calf at birth. Most participants did not support these practices. Provision of brief explanatory information played a minor role in influencing people's views, but failed to result in general acceptance.

\section{ACKNOWLEDGMENTS}

This research was funded by the Science Without Borders Program (CNPq, National Council for Scientific and Technological Development, Brasilia, Brazil; Grant No. 400850/2013-3), which also provided funding to Marina A.G. von Keyserlingk to facilitate her stay in Brazil. Maria J. Hötzel and Angelica Roslindo were supported by CNPq. Clarissa S. Cardoso was supported by FAPESC (Fundação de Amparo à Pesquisa e Inovação do Estado de Santa Catarina, Florianópolis, Brazil). General support for Marina von Keyserlingk is provided by the Natural Sciences and Engineering Program of Canada's (Ottawa, Canada) Industrial Research Chair Program in Animal Welfare.

\section{REFERENCES}

Asheim, L. J., J. F. Johnsen, Ø. Havrevoll, C. M. Mejdell, and A. M. Grøndahl. 2016. The economic effects of suckling and milk feeding to calves in dual purpose dairy and beef farming. Rev. Agric. Food Environ. Stud. 97:225-236. https://doi.org/10.1007/s41130016-0023-4.

Balcão, L. F., C. Longo, J. H. C. Costa, C. Uller-Gómez, L. C. P. Machado Filho, and M. J. Hötzel. 2017. Characterization of smallholding dairy farms in southern Brazil. Anim. Prod. Sci. https:// doi.org/10.1071/AN15133.

Benard, M., and T. de Cock Buning. 2013. Exploring the potential of Dutch pig farmers and urban-citizens to learn through frame reflection. J. Agric. Environ. Ethics 26:1015-1036.

Bennett, R. M., P. J. Jones, C. J. Nicol, R. B. Tranter, and C. A. Weeks. 2016. Consumer attitudes to injurious pecking in free-range egg production. Anim. Welf. 25:91-100.

Boogaard, B. K., B. B. Bock, S. J. Oosting, J. S. C. Wiskerke, and A. J. van der Zijpp. 2011. Social acceptance of dairy farming: The ambivalence between the two faces of modernity. J. Agric. Environ. Ethics 24:259-282.

Boogaard, B. K., S. J. Oosting, and B. B. Bock. 2008. Defining sustainability as a socio-cultural concept: Citizen panels visiting dairy farms in the Netherlands. Livest. Sci. 117:24-33.
Brom, F. W. A. 2000. Food, consumer Ccncerns, and trust: Food ethics for a globalizing market. J. Agric. Environ. Ethics 12:127-139.

Capper, J. L. 2011. Replacing rose-tinted spectacles with a high-powered microscope: The historical versus modern carbon footprint of animal agriculture. Anim. Front. 1:26-32.

Cardoso, C. S., M. J. Hötzel, D. M. Weary, J. A. Robbins, and M. A. G. von Keyserlingk. 2016. Imagining the ideal dairy farm. J. Dairy Sci. 99:1663-1671.

Clark, B., G. B. Stewart, L. A. Panzone, I. Kyriazakis, and L. J. Frewer. 2016. A systematic review of public attitudes, perceptions and behaviours towards production diseases associated with farm animal welfare. J. Agric. Environ. Ethics 29:455-478.

Costa, J. H. C., M. J. Hötzel, C. Longo, and L. F. Balcão. 2013 A survey of management practices that influence production and welfare of dairy cattle on family farms in southern Brazil. J. Dairy Sci. 96:307-317.

Cozzi, G., F. Gottardo, M. Brscic, B. Contiero, N. Irrgang, U. Knierim, O. Pentelescu, J. J. Windig, L. Mirabito, F. K. Eveillard, A. C. Dockes, I. Veissier, A. Velarde, C. Fuentes, A. Dalmau, and C. Winckler. 2015. Dehorning of cattle in the EU Member States: A quantitative survey of the current practices. Livest. Sci. 179:4-11.

Croney, C. C., M. Apley, J. L. Capper, J. A. Mench, and S. Priest 2012. Bioethics symposium: The ethical food movement: What does it mean for the role of science and scientists in current debates about animal agriculture? J. Anim. Sci. 90:1570-1582.

Cuite, C. L., H. L. Aquino, and W. K. Hallman. 2005. An empirical investigation of the role of knowledge in public opinion about GM food. Int. J. Biotechnol. 7:178-194.

dos Santos, G., and C. M. M. Bittar. 2016. A survey of dairy calf management practices in some producing regions in Brazil. Rev. Bras. Zootec. 44:361-370.

Ellis, K. A., K. Billington, B. McNeil, and D. E. F. McKeegan. 2009. Public opinion on UK milk marketing and dairy cow welfare. Anim. Welf. 18:267-282.

Foley, J. A., N. Ramankutty, K. A. Brauman, E. S. Cassidy, J. S. Gerber, M. Johnston, N. D. Mueller, C. O'Connell, D. K. Ray, P. C. West, C. Balzer, E. M. Bennett, S. R. Carpenter, J. Hill, C. Monfreda, S. Polasky, J. Rockstrom, J. Sheehan, S. Siebert, D. Tilman, and D. P. M. Zaks. 2011. Solutions for a cultivated planet. Nature 478:337-342.

Fraser, D. 2001. The "New Perception" of animal agriculture: Legless cows, featherless chickens, and a need for genuine analysis. J. Anim. Sci. 79:634-641.

Fraser, D., D. M. Weary, E. A. Pajor, and B. N. Milligan. 1997. A scientific conception of animal welfare that reflects ethical concerns. Anim. Welf. 6:187-205.

Frewer, L. J., D. Coles, L.-M. Houdebine, and G. A. Kleter. 2014. Attitudes towards genetically modified animals in food production. Br. Food J. 116:1291-1313.

Fulwider, W. K., T. Grandin, B. E. Rollin, T. E. Engle, N. L. Dalsted, and W. D. Lamm. 2008. Survey of dairy management practices on one hundred thirteen north central and northeastern United States dairies. J. Dairy Sci. 91:1686-1692.

Godfray, H. C. J., I. R. Crute, L. Haddad, D. Lawrence, J. F. Muir, N. Nisbett, J. Pretty, S. Robinson, C. Toulmin, and R. Whiteley. 2010. The future of the global food system. Philos. Trans. R. Soc. Lond. B Biol. Sci. 365:2769-2777.

Gremmen, B., and V. Blok. 2016. The lesser of two evils? The killing of day-old male chicks in the Dutch egg sector. Pages $72-75$ in Food Futures. I. A. S. Olsson, S. M. Araújo, and M. F. Vieira, ed. Wageningen Publishers, Wageningen, the Netherlands.

Hansen, J., L. Holm, L. Frewer, P. Robinson, and P. Sandøe. 2003. Beyond the knowledge deficit: recent research into lay and expert attitudes to food risks. Appetite 41:111-121.

Harvey, D., and C. Hubbard. 2013. Reconsidering the political economy of farm animal welfare: An anatomy of market failure. Food Policy 38:105-114.

Heerwegh, D. 2009. Mode differences between face-to-face and web surveys: an experimental investigation of data quality and social desirability effects. Int. J. Public Opin. Res. 21:111-121. 
Hötzel, M. J. 2016. Letter to the editor: Engaging (but not "educating") the public in technology developments may contribute to a socially sustainable dairy industry. J. Dairy Sci. 99:6853-6854.

Hötzel, M. J., C. Longo, L. F. Balcão, C. S. Cardoso, and J. H. C Costa. 2014. A survey of management practices that influence performance and welfare of dairy calves reared in southern Brazil. PLoS One 9:e114995.

Huberman, A. M., and M. B. Miles. 1994. Data management and analysis methods. Page 643 in Handbook of qualitative research. N. K. Denzin and Y. S. Lincoln, ed. SAGE, Thousand Oaks, CA.

IBGE. 2010. Censo Demográfico 2010. Accessed May 8, 2014. http:// www.sidra.ibge.gov.br/cd/cd2010agsub.asp.

Jardim, A. N. O., and E. D. Caldas. 2012. Brazilian monitoring programs for pesticide residues in food - Results from 2001 to 2010 Food Contr. 25:607-616.

Lassen, J., P. Sandøe, and B. Forkman. 2006. Happy pigs are dirty! conflicting perspectives on animal welfare. Livest. Sci. 103:221230

Lu, Y. 2013. Consumer preference for eggs from enhanced animal welfare production system: a stated choice analysis. Page 139 in Food, Agricultural and Resource Economics. Master's thesis. University of Guelph, Guelph, Ontario, Canada.

Lusk, J. L., and F. B. Norwood. 2010. Direct versus indirect questioning: an application to the well-being of farm animals. Soc. Indic. Res. 96:551-565.

Macnaghten, P. 2004. Animals in their nature: A case study on public attitudes to animals, genetic modification and 'Nature'. Sociology 38:533-551.

Mee, J. F. 2008. Newborn dairy calf management. Vet. Clin. North Am. Food Anim. Pract. 24:1-17.

Miele, M. 2010. Report concerning consumer perceptions and attitudes towards farm animal welfare. Official Experts Report EAWP (task 1.3). Uppsala University, Uppsala, Sweden.

Minayo, M. C. S. 2008. O Desafio do Conhecimento. Hucitec, São Paulo, Brazil.

Movimentos Sociais e Redes. 2016 Campanha permanente contra os agrotóxicos e pela vida. Accessed Jul. 22, 2016. http://www. contraosagrotoxicos.org/index.php/campanha.

Nuffield Council on Bioethics. 2015. Ideas about naturalness in public and political debates about science, technology and medicine Analysis paper. Nuffield Council on Bioethics, London, UK.

Oliveira, E., and C. Bonfanti. 2014. Antibiótico, e não hormônio, é o maior risco em carnes e frangos (Antibiotics, not hormones, are the greatest risk in beef and poultry). O Globo. Infoglobo Comunicação e Participações S.A., Brasília, Brazil. Accessed Feb. 14, 2017. http://oglobo.globo.com/economia/defesa-do-consumidor/antibiotico-nao-hormonio-o-maior-risco-em-carnes-frangos-13551827\#ixzz4NKyofnft.

Pettersson, I. C., C. A. Weeks, L. R. M. Wilson, and C. J. Nicol. 2016. Consumer perceptions of free-range laying hen welfare. Br. Food J. 118:1999-2013.

Pieper, L., M. G. Doherr, and W. Heuwieser. 2016. Consumers' attitudes about milk quality and fertilization methods in dairy cows in Germany. J. Dairy Sci. 99:3162-3170.

Prickett, R. W., F. B. Norwood, and J. L. Lusk. 2010. Consumer preferences for farm animal welfare: results from a telephone survey of US households. Anim. Welf. 19:335-347.

Ribeiro, T. G., B. Barone, and J. H. Behrens. 2016. Genetically modified foods and their social representation. Food Res. Int. 84:120127 .

Richards, T., W. Allender, and D. Fang. 2013. Media advertising and ballot initiatives: the case of animal welfare regulation. Contemp. Econ. Policy 31:145-162.

Robbins, J. A., B. Franks, D. M. Weary, and M. A. G. von Keyserlingk. 2016. Awareness of ag-gag laws erodes trust in farmers and increases support for animal welfare regulations. Food Policy $61: 121-125$.

Robbins, J. A., D. M. Weary, C. A. Schuppli, and M. A. G. von Keyserlingk. 2015. Stakeholder views on treating pain due to dehorning dairy calves. Anim. Welf. 24:399-406.
Robson, C. 1993. Real World Research: A Resource for Social Scientists and Practitioner-Researchers. Blackwell, Oxford, UK.

Rodrigues, A. 2014. Um milhão de litros do leite adulterado foram colocados à venda, diz Ministério Público (One million liters of adulterated were offered for sale according to Public Ministry). Empresa Brasil de Comunicação S/A - EBC, Brasília, Brazil Accessed Feb. 14, 2017. http://www.ebc.com.br/noticias/ brasil/2014/05/cerca-de-1-milhao-de-litros-de-leite-adulteradoforam-colocados-a-venda-diz.

Ryan, E. B., D. Fraser, and D. M. Weary. 2015. Public attitudes to housing systems for pregnant pigs. PLoS One 10:e0141878.

Schuppli, C. A., M. A. G. von Keyserlingk, and D. M. Weary. 2014. Access to pasture for dairy cows: Responses from an online engagement. J. Anim. Sci. 92:5185-5192.

Spers, R. G., J. T. C. Wright, and A. A. Amedomar. 2013. Scenarios for the milk production chain in Brazil in 2020. Rev. Adm. (São Paulo) 48:254-267

Stafford, K. J., and D. J. Mellor. 2011. Addressing the pain associated with disbudding and dehorning in cattle. Appl. Anim. Behav. Sci. 135:226-231.

Tonsor, G. T., and C. A. Wolf. 2010. Drivers of resident support for animal care oriented ballot initiatives. J Agric. Appl. Econ. 42:419-428.

van Asselt, M., E. D. Ekkel, B. Kemp, and E. N. Stassen. 2016. Role of moral values in the trade-off between animal welfare and food safety risks in broiler husbandry. Pages $273-278$ in Food Futures. I. A. S. Olsson, S. M. Araújo, and M. F. Vieira, ed. Wageningen Publishers, Wagneingen, the Netherlands.

Vanhonacker, F., W. Verbeke, E. Van Poucke, and F. A. M. Tuyttens 2008. Do citizens and farmers interpret the concept of farm animal welfare differently? Livest. Sci. 116:126-136.

Vasseur, E., F. Borderas, R. I. Cue, D. Lefebvre, D. Pellerin, J. Rushen, K. M. Wade, and A. M. de Passille. 2010. A survey of dairy calf management practices in Canada that affect animal welfare. J. Dairy Sci. 93:1307-1315.

Ventura, B. A., M. A. G. Von Keyserlingk, C. A. Schuppli, and D. M. Weary. 2013. Views on contentious practices in dairy farming: The case of early cow-calf separation. J. Dairy Sci. 96:6105-6116.

Ventura, B. A., M. A. G. von Keyserlingk, H. Wittman, and D. M. Weary. 2016. What difference does a visit make? Changes in animal welfare perceptions after interested citizens tour a dairy farm. PLoS One 11:e0154733.

Verhoog, H., M. Matze, E. L. van Bueren, and T. Baars. 2003. Role of the concept of the natural (naturalness) in organic farming. J. Agric. Environ. Ethics 16:29-49.

von Keyserlingk, M. A. G., and M. J. Hötzel. 2015. The ticking clock: Addressing farm animal welfare in emerging countries. J. Agric. Environ. Ethics 28:179-195.

von Keyserlingk, M. A. G., N. P. Martin, E. Kebreab, K. F. Knowlton, R. J. Grant, M. Stephenson II, C. J. Sniffen, J. R. Harner III, A. D. Wright, and S. I. Smith. 2013. Invited review: Sustainability of the US dairy industry. J. Dairy Sci. 96:5405-5425.

Weary, D. M., L. Niel, F. C. Flower, and D. Fraser. 2006. Identifying and preventing pain in animals. Appl. Anim. Behav. Sci. 100:64-76.

Weary, D. M., B. A. Ventura, and M. A. G. von Keyserlingk. 2016 Societal views and animal welfare science: Understanding why the modified cage may fail and other stories. Animal 10:309-317.

Winder, C. B., S. J. LeBlanc, D. B. Haley, K. D. Lissemore, M. A Godkin, and T. F. Duffield. 2016. Practices for the disbudding and dehorning of dairy calves by veterinarians and dairy producers in Ontario, Canada. J. Dairy Sci. 99:10161-10173. https://doi. org/10.3168/jds.2016-11270.

Wolf, C. A., G. T. Tonsor, M. G. S. McKendree, D. U. Thomson, and J. C. Swanson. 2016. Public and farmer perceptions of dairy cattle welfare in the United States. J. Dairy Sci. 99:5892-5903.

You, X., Y. Li, M. Zhang, H. Yan, and R. Zhao. 2014. A survey of Chinese citizens' perceptions on farm animal welfare. PLoS One 9:e109177 